\title{
Collaborative Innovation Center as a New Service System to Drive Economic Development
}

\author{
Qiqing (Christine) Ouyang \\ IBM Corporation \\ Yorktown Heights, NY, USA \\ couyang@us.ibm.com
}

\author{
Stephen Perelgut \\ IBM Canada \\ Markham, ON, Canada
}

\author{
Jim Spohrer \\ IBM Corporation \\ San Jose, CA, USA
}

\begin{abstract}
This paper describes a model for a new service system, Collaborative Innovation Centers (CIC) that IBM has instituted to work with regional government, academia and business. While education, research and entrepreneurship are generally the three pillars of a CIC, the center can be tailored to emphasize one or two out of the three areas to meet the needs of all stakeholders. The CIC service system has proven to be a successful model for building a healthy ecosystem of public and private sector partnerships fueled by common goals and individual constraints, and enabled by shared resources, in-demand skills, and innovation. While the individual CIC goals may differ, regional economic development is a consistent outcome.
\end{abstract}

Keywords- collaboration; innovation; skills; entrepreneurship; ecnomic development; service system.

\section{INTRODUCTION}

Long-term sustainable economic development is shaped by the value created by both individuals and businesses, leveraging technology as an accelerator for growth. It requires people putting their talents to use within efficient and innovative business and social systems that create value and economic growth. Cities, regions or countries without the right talent cannot successfully develop and adopt improved technologies [1]. However, rapid technology evolution has resulted in growing skills gaps and challenges for educators and trainers to produce relevant, highly skilled graduates. Only 1 out of 10 organizations surveyed has all the skills it needs to be successful while 3 out 4 students and educators report a moderate to major gap in their ability to meet the skill needs of the IT workforce [2]. The US Bureau of Labor Statistics indicates that, over the past century, it takes about 10 years to catch up with a technology disruption - as measured by productivity levels [3]. Working alone, academic institutions are generally not set up to detect these changing trends or to respond to the rapidly evolving nature of future talent demands.

Yet higher education plays a critical role in economic growth, scientific progress and social development. As complex service systems themselves, universities make a significant contribution to localities as a source of employment, expenditure, knowledge, and in particular, talent supply. Many universities, especially the ones with a medical center or hospital, are the largest employers in their own regions. Undoubtedly, universities are often the driving force for regional economic development. On the other hand, universities rely heavily on the support of local communities. A close correlation between universities and regional economy at the national level has been identified in [4]. With the most recent data for 2012, Figure 1 shows nations' percentage of global GDP versus percentage of top 500 universities. United States is "off the chart" with $21 \%$ global GDP and $30 \%$ of top university in worldwide top 500. China and other large population emerging markets are rising rapidly. In the past eight years, China moved up $[+6.8 \%,+5.2 \%]$, while US moved down $[-6.4 \%,-4.0 \%]$. Furthermore, China is predicted to be "off the chart" in less than 10 years.

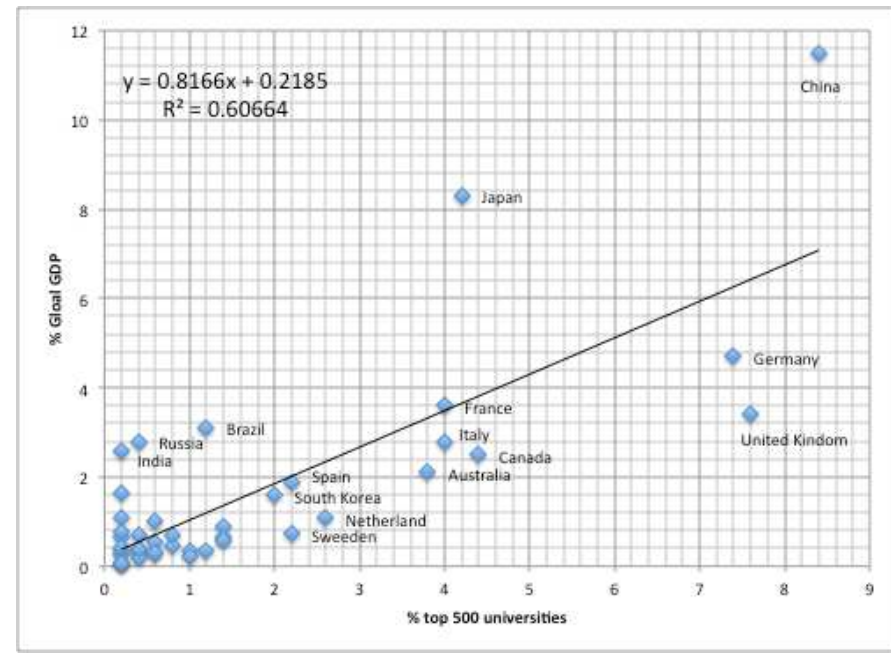

FIGURE I. PERCENTAGE OF GLOBAL GDP VERSUS PERCENTAGE OF TOP-500 UNIVERSITIES IN 2012 (SOURCE [5-6])

Regions and countries with agile economics achieve a successful balance between business and talent that leverages the development and adoption of technology and innovation to achieve sustainable economic growth. They are able to attract, develop and retain indigenous talent while leveraging the potential of technology. The presence of these dynamic businesses generates job opportunities, which, in turn, attracts more talent and improves the attraction, retention and development of innovative businesses [7].

As a response to the Triple Helix [8] model of how economic growth is encouraged by collaboration between the private, public and academic sectors, IBM began to develop a new program called Collaborative Innovation Centers in 2010, to address the skills gaps, grow business and help rejuvenate regional economies. From a Triple Helix systems perspective, the consolidation of the spaces and the non-linear interactions 
between government, academia and private companies can generate new combinations of knowledge and resources that can advance innovation theory and practice, especially at the regional level [9].

\section{EARLY COLLABORATION EXAMPLES}

IBM has a long tradition of collaborating with academic researchers. Built 1951, IBM University Programs now works with over 5000 universities around the world, creating relationships around the 6 R's: Research, Readiness, Recruiting, Revenue, Responsibility, and Regions [10].

During the past decade, as an information technology (IT) company serving government, university and companies across all industry sectors, IBM has become a catalyst for radical collaboration. For example, in 2004, State of New York, State University of New York at Albany and IBM jointly developed Albany NanoTech Complex (ANT). ANT is now a fully-integrated research, development, prototyping, and educational facility for nanotechnology that provides strategic support through outreach, technology acceleration, business incubation, pilot prototyping, and test-based integration support for onsite corporate partners including IBM, TEL, Applied Materials, ASML and International SEMATECH, as well as other "next generation" nanotechnology research activities. By creating an ecosystem for the semiconductor industry, the new Silicon Valley is now located in New York. Global Foundry has built two the most advanced $300 \mathrm{~mm}$ Fabs in the world in Saratoga County, New York. With a total of \$7 billion invested and thousands of jobs created, it is the largest commercial economic development project in the USA. IBM has helped make New York State one of the world's premier locations for semiconductor design and manufacturing. The radical collaboration is now being taught at the Harvard Business School [11].

Another example is the IBM Centre for Business Analytics and Performance at the University of Ottawa. This model led to the Center of Advanced Studies (CAS) Atlantic collaboration with the University of New Brunswick and the Atlantic Canada Opportunities Agency in 2006. It then evolved into the IBM Canada Research and Development Centre (CRDC) and the partnership with 7 Ontario universities, the Southern Ontario Smart Computing Innovation Platform (SOSCIP) and then to the Consortium for Analytics Research, Education and Training (CARET) with IBM, the Nova Scotia Government and 7 academic institutions in Nova Scotia in 2012 [12]. In Nova Scotia, the economic impact has been estimated to grow in excess of $\$ 100 \mathrm{M}$ per year. Now there are more than 20 IBM Centers for Advanced Studies (CAS) [13], where we work with more than 50 universities, supporting a growing number of IBM Research collaboratories in major cities worldwide.

\section{COllaborative INNOVATION CENTERS}

The Collaborative Innovation Center (CIC) was developed based on best practice so that it can be replicated or scaled out to other regions quickly. As a service system and a regional wealth engine, CIC provides an overarching framework to better facilitate the collaboration among public and private sectors. The CIC requires investment from all stakeholders initially, but aims to become self-sustainable in three to five years. The model befits a variety of forms and the solution is flexible and creative. All of the stakeholders benefit from shared resource (reduced costs), learning, serendipity, reduced risk and faster time to value.

\section{A. Selection process}

The demand on CICs has grown rapidly in the past three years, as more and more universities and government agencies became aware of this program. Therefore, it is necessarily to prioritize where, when and with whom to set up large scale CICs, in order to make the most impact. An analytical framework is used to identify the right partners, as shown in Figure 2 and Figure 3.

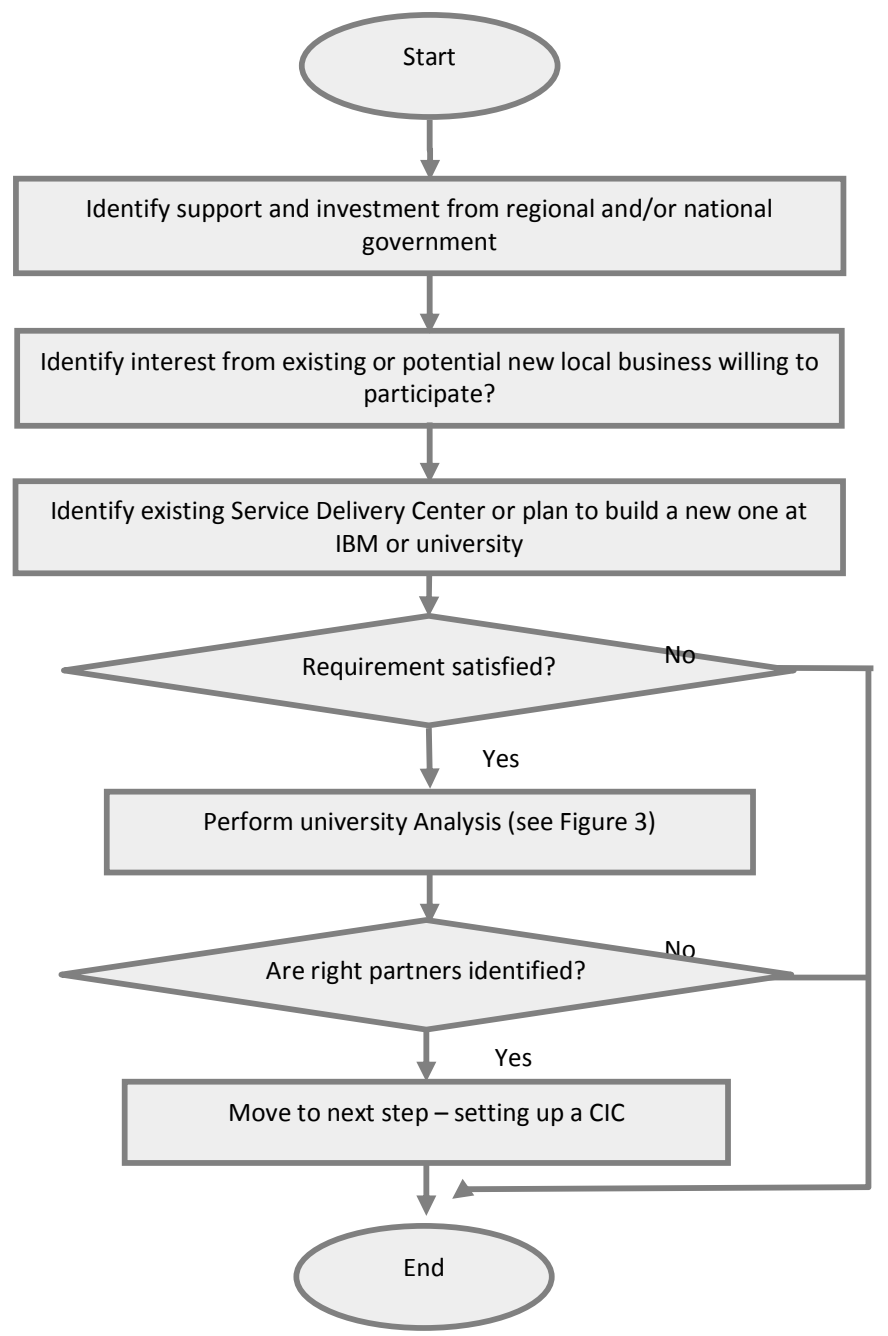

FIGURE II. PARTNER SELECTION PROCESS FOR CICS. 


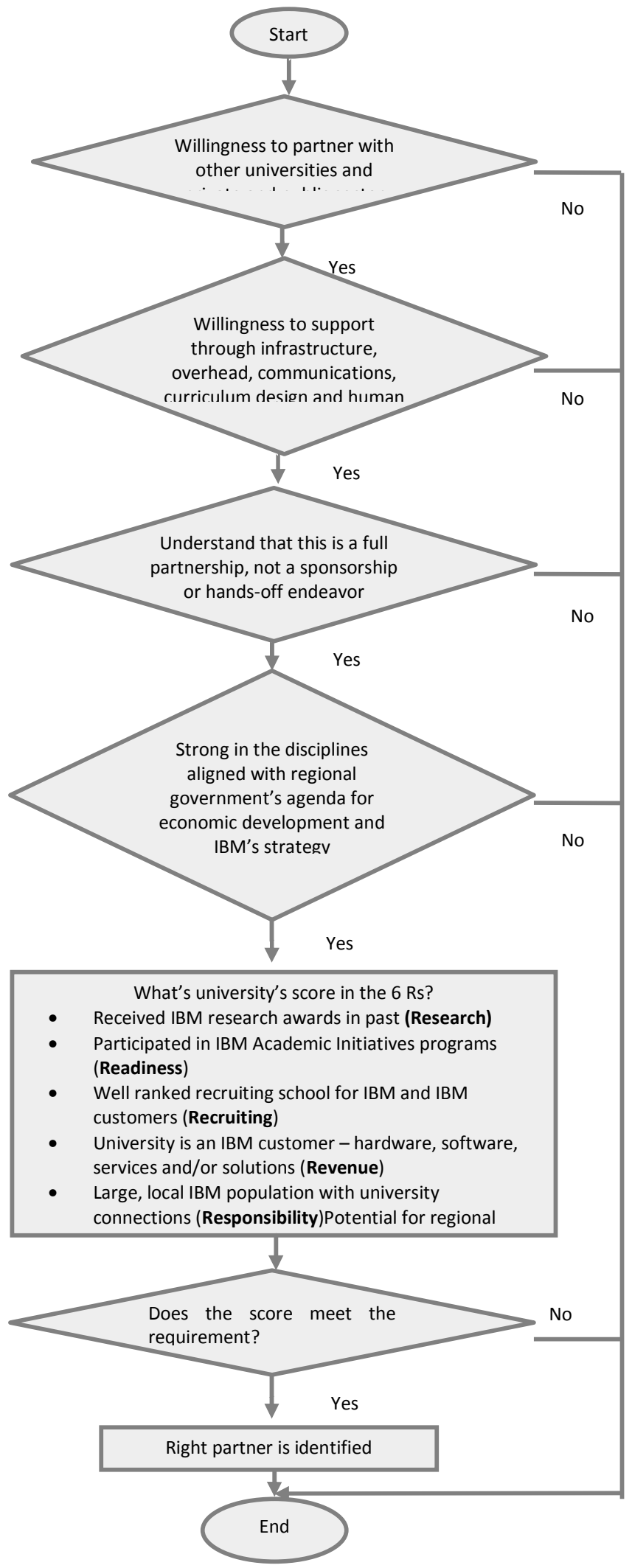

FIGURE III .UNIVERSITY ANALYSIS USED IN THE SELECTION PROCESS.

\section{B. How to set up CIC}

Setting up a CIC is a rigorous process over multiple months. After partner selection, tasks include: mapping out stakeholders' common interest, creating a mission statement and a roadmap with milestones and timeline for the CIC, constructing a Steering Committee and a working team, defining the scope of work, estimating the cost including capital expense and operation expense, identifying resources, developing a business/financial model, signing an agreement, and arranging public announcement, etc. Normally, a weekly cadence call is used to monitor the progress until the center is established.

\section{1) Value propositions}

Companies such as IBM bring vast intellectual property, world-class experts and innovation leadership. This collaborative engagement creates a diversity of viewpoints, backgrounds and expertise that enables profound new, significant solutions in strategic technology areas. Because of companies' reach and ecosystem partners, local innovations have the potential to be scaled globally, rapidly, and profitably for all stakeholders. This is especially true for innovations aligned with companies' initiatives (e.g., for IBM, Smarter Planet, Smarter Cities, Cloud Computing, Big Data Analytics, Social Business, Cyber Security, Cognitive Computing, etc.).

Though CICs, companies not only harvest needed skills from a large talent pool, but also get new technologies faster to market. Regional governments get increased tax revenues and can provide better public services. Universities benefit from enhanced brand equity that helps attract better students and faculty.

\section{2) Ownership and business model}

CIC is usually co-located on the same site as the universities. In some cases, CIC is university-owned and operated entities; in others, they can be part of an IBM service delivery center, owned and operated by IBM. A joint ownership is also a possibility, though it may be difficult to operate. Other academic institutions and private companies may become partners in the center or pay a membership fee to have access to the center resources. Often member companies are motivated by access to student interns or potential employees with experience working on real-world challenges, with real-world tools, on real-world data, with real-world mentors.

The business model includes an initial government or regional economic development group investment to establish the CIC. The CIC must then become self-sufficient based on tuition fees, corporate membership fees, and expanded regional revenues. Both academic and industry faculty are directly supported by tuition fees, and indirectly by the starting salaries of the graduates. The initial government investment is justified by an increase in high-skill, high-pay labor paying taxes in the region, as well as new innovative firms based in the region.

The business model is highly flexible, allowing for different partners that participate with different levels of 
intensity. In many cases, the regional economic benefits will attract intense investment from the public sector and the center will be modeled as a not-for-profit or even as a nongovernmental organization. In other cases, it will be used as a marketing and revenue-generating vehicle by the academic institution, which provides education and training on a costrecovery or profit-making basis. For participating private sector businesses, the CIC is not seen as primarily an economic effort but rather as a training and skills-enablement vehicle.

\section{3) Governance}

Each CIC has a well-formed governance model that meets the needs of the individual situations. The template recommends that there be a Steering Committee (SC) to provide oversight. The SC consists of executives from the universities and private sector partners and it may or may not involve regional government participation - usually in a nonvoting role. The Center Director typically reports to SC.

The SC provides oversight and guidance for the remaining committees and is responsible for communications outside the center. This might extend to establishing a separate Communications Committee or simply managing an external presence through online tools such as websites or through emails and newsletters.

To the extent that funding and other resources are involved, the SC plays a role similar to a Board of Directors, offering advice and counsel to the Director and, ultimately, being responsible for the success of the CIC.

\section{4) Scope of work -- three pillars}

A common theme in all CICs is integrated learning (teaching/skills), discovery (research), and engagement (application/entrepreneurship) on real-world challenges. The focus is on real-world challenges, real-world tools, real-world data, real-world mentors, and leading-edge teaching and research faculty that expand the professional social networks of the students. While education, research and entrepreneurship are the three pillars of CICs', the model is flexible and can be easily modified to meet the regional needs.

\section{a) Education and Training}

One of the most important goals of the CIC is to build competency for new technology and design a regional workforce with $\mathrm{T}$-shaped professionals (depth and breadth) that keeps jobs locally. Typically, universities are very good at producing I-shaped graduates with depth, but lack of adaptive capacity, innovation capacity, teamwork capacity, and boundary-spanning breadth. T-shaped professionals have breadth, and a special type of empathy that motivates them to learn about the expertise areas of their teammates. T-shaped professionals are adaptive innovators, highly-socially networked, lifelong learners, and make excellent entrepreneurs. If skills development is the primary goal of the CIC, it is sometimes called a Center of Competency $(\mathrm{CoC})$ or Center of Excellence $(\mathrm{CoE})$.
Teaching can take the form of improving existing courses including upgrading to the latest technologies for expressing concepts in the course. This has the least invasive impact although the results are not as directly monitored. Where the innovation is the result of a significant evolution of existing technologies, a new course might be added to a degree program. Adding a new course is a much larger commitment of time and cannot happen overnight but the results are more immediate and can be verified. The partnership of private sector (providing tools and expertise) and academia (providing educational know-how and delivering the materials) is powerful.

For substantial evolutions of technology, there may be opportunities to further expand to offer a minor, major, or even a specialist designation within a program. These may not take effect for a year and may not deliver graduates until three years or longer after the decision but they are substantial and graduates will be highly sought after. In some instances, this might expand to a full degree program but the timing can be onerous with years to prepare (depending on the policies in the region) and approve the degree followed by 4 (or even 5) more years for students to sign up and progress through the program.

Another route to take is developing graduate programs, especially professional Masters Programs that can often be developed in a year with 18 more months for intake, education and graduation. The more traditional graduate programs involve more rigorous (and time consuming) processes but may be warranted depending on circumstances.

Other choices are focused on skills development and training. These could take the place of post-graduate diploma or certificate programs, certification (where an appropriate certifying body exists), and even individual continuing education courses. Where business partners are actively involved, the academic partner might offer to develop in-house training programs.

\section{b) Research and Think Tank}

Since the materials in question are state-of-the-art developments, they represent a potential for academic research, which, in turn, helps focus academic attention on the innovative technology and grant challenges that our society is facing.

In particular, the Analytics environment is vastly different from the recent past with the exponentially increasing amount of data available, the exponentially increasing compute power, and the evolution of Business Analytics, Social Analytics, Content Analytics, Information Based Governance, etc. Many universities are creating centers of studies for related topics and, where there is a regional need for skills, it makes sense for a corporate sponsor such as IBM to step up and support the research with hardware, software, professional expertise, etc.

This aspect is also important for the academic partners in the CIC since it motivates them and supports their key performance objectives. Research provides a unique way for the most highly qualified students to learn both practical and 
academic skills in the context of the new technologies. On the other hand, advanced research also helps improving the overall ranking of academic institutions.

As to the government, the CIC is a think tank for policy studies and setting future directions for regional growth. Governments can use the resource for applications crucial to national security, public safety and the environment. In addition, material-flow-analysis, energy-flow-analysis, talentflow-analysis can inform policy makers who advise regional economic development boards. The unique collaboration will result in highly skilled graduates that are focused by the CIC to specific competencies, which represent an employable skills base that is only useful in attracting businesses that need those skills.

\section{c) Entrepreneurship (start-ups and spin-offs)}

The third pillar of the Center is proactively putting knowledge to use and creating direct impact on social and economic development. By definition, the collaborative innovation is interactive rather than a linear model of innovation, which can generate higher levels of training and in sharing of knowledge. Government can act as a public entrepreneur and venture capitalist. As universities develop connections, they can combine discrete pieces of intellectual property and jointly exploit them. The academic 'third mission' - involvement in socio-economic development, next to the traditional missions of teaching and research, is most salient in the Entrepreurial University [14].

A recent study [15] has found that University spin-offs are more innovative, more successful than comparable firms because of the characteristics that are specific to spin-offs, such as high R\&D intensity, high cooperation frequency, and the location of the business. The analysis also reveals that university spin-offs are more likely to hold patents, whereas the research institute spin-offs are more likely to have introduced radical product innovations. Thus, the initial endowment and knowledge transfer from the parent institution would explain the superior innovation performance of spinoffs.

IBM Global Entrepreneur Initiative provides startups with access to world-class advisors and IBM support, free software and technology, and an extensive network of global experts, VCs, and investors. IBM SmartCamps are exclusive events aimed at identifying early stage entrepreneurs who are developing business ventures that align with our IBM Smarter Planet vision. SmartCamps enable startups to take advantage of mentoring opportunities, learn from thought leaders, and network with serial entrepreneurs, investment firms, academic institutions, and industry and technology experts. They also give selected startups the opportunity to connect with the venture community.

\section{5) Resources and infrastructure support}

In addition to human and financial resources, another important factor in successful CICs access to leading-edge technical infrastructure. Many of these technologies need a complex environment to support the simplified front end. For example, Big Data Science requires huge storage (petabytes and exabytes) and high performance computing (in the 100's of teraflops or beyond). It can be challenging for academic partners to afford the capital costs and the operational expense, as well as the challenge of pulling together a skilled support team.

Fortunately, infrastructure as a service (IaaS) including Cloud Computing is becoming increasingly ubiquitous. Many IT (Information Technology) corporate partners have university award programs that include provisioning an initial starting set of hardware, software and expertise. The full range of equipment, tools and people will be an extension of the initial setup, and it can evolve over time as evidence of the importance and value of the CIC accumulate, making the later enhancements more feasible.

For example, the previously described SOSCIP used a Cloud Computing infrastructure that allowed multiple parties to share the expensive infrastructure. Free or affordable access to computing and storage as a service, can complement stand-alone systems used to provide regional expertise development in data center operations. Amazon Web Services provides cloud computing for a fee, and free offering such as IBM's World Community Grid hold competitions to identify worthy projects with broad societal impact.

Research Computing [16] has evolved to be a model that government, academia and business jointly invest in IT infrastructure and build up the computing capability for the community. The private sector partners can be indispensable by providing an initial starting set of hardware, software and expertise to help establish the value of the skills development and research. The full range of equipment, tools and people will be an extension of the initial setup but it can evolve over time, with a strong evidence of the importance and value, making the later enhancements more feasible.

Many research computing partnerships have helped solve complex interdisciplinary problems; sometimes creating whole new industries, e.g. nanotechnology and biotechnology; reinforcing the virtuous cycle of economic development through innovation.

\section{Results}

Internationally, the model has evolved to meet the combined needs of government, industry and academia in a number of regions including: Columbus Ohio, Philippines, Milan Italy, Singapore, and most recently, Barton Rouge Louisiana. Each center evolves independently to meet the local needs and to fit the local resources, but there is a commonality that simplifies the process and encourages rigor and results.

With the current success, and the advent of highly skilled graduates, the model is taking root in even more jurisdictions and we anticipate a total economic benefit worldwide that is in excess of \$1B per year within the next few years. Further, the regional developments should result in associated economic 
growth that can be evaluated and linked to the CIC where appropriate.

\section{FUTURE WORK}

The CIC model has three directions for growth. First, it is poised to expand into new regions around the world as opportunities are identified. Second, there is the application to new technologies as demand grows rapidly. Example of these technologies would include Cloud Computing, Mobile Technology, Social Business, Risk Management, Cyber Security, etc. Moreover, there is also a demand to focus CICs on specific application domains such as healthcare, water management and sustainable energy. As new technologies and business practices evolve, they create new demands and new opportunities in many different areas and an application domain specific CIC could be defined.

The corporate support, including financial, technical and human resource, needs a more rigorous governance process.

More research is needed on how to continuously evolve courses year over year in times of accelerating change.

\section{CONCLUSIONS}

The CIC model has evolved over the past several years and has now become a standard, although highly flexible, template for corporate support of regional economic development through skills generation, research enablement and entrepreneurship creation. The successful implementations around the world have proved that the concept is sound and the implementation is feasible.

Service systems are defined as dynamic configurations of resources (e.g, people, technology, information, and organizations) interconnected internally and externally by value propositions [17]. While CICs as a type of service system are relatively new, they are in fact just one more step in an ongoing evolution of prior public-private partnerships, but in the age of infrastructure as a service. As the era of cognitive systems dawns, and service systems get smarter, we expect to see even more evolution of CICs [18-19].

\section{ACKNOWLEDGMENT}

The authors would like to thank Dr. Bernard Meyerson of IBM Corporation and Marcellus Mindel of IBM Canada Ltd who were instrumental in forming some of these concepts. The authors would also like to thank Marisa Viveros, Lilian $\mathrm{Wu}$,
Dianne Fodell and Joann W. Winson of IBM Corporation for their strong support in setting up some of the CICs.

\section{REFERENCES}

[1] S. Dirks, C. Gurdgiev and M. Keeling, "Smarter cities for smarter growth: How cities can optimize their systems for the talent-based economy," IBM Institute for Business Value, May 2010.

[2] J. Lo, C. Wyble and S. Hupfer, "Fast track to the future", The 2012 IBM Tech Trends Report.

[3] J. Manyika, D. Hunt, S. Nyquist, J. Remes, V. Malhotra, L. Medonca, ... "Growth and Renewal in the United States: Retooling America's Economic Engine,” Journal of Applied Corporate Finance, 23(1), 8-19. 2010.

[4] G. Lella, A. Fischetto, V. Cesarotti, J. Spohrer, G. Ren \& Y. Leung, "Universities as complex service systems: External and Internal perspectives," Service Operations and Logistics, and Informatics (SOLI), 2012 IEEE International Conference on, pp. 422-427.

[5] http://www.shanghairanking.com/ARWU-Statistics-2013.html

[6] GDP 2012 List by the World Bank (1990-2012).

[7] D. Jacob, "Improving economics competitiveness and vitality," IBM Institute for Business Value, October 2013.

[8] H. Etzkowitz, The Triple Helix: University-Industry-Government Innovation In Action, Routledge, London, 2008.

[9] R. Hausmann, C. Hidalgo, S. Bustos, M. Coscia, S. Chung, J. Jimenez, A. Simoes, and M. Yildirim. "The atlas of economic complexity." Boston, USA, 2011.

[10] J. Spohrer, 'IBM's University Programs," Industry Perspective, Computer Magazine, IEEE Computers Society, pp. 84-86, August 2010.

[11] W. Shih, G. Pisano, A. King, "Radical Collaboration: IBM Microelectronics joint development alliances," Harvad Business School, November 2008.

[12] S. Perelgut, Q. Ouyang and D. Fodell, accepted by First International Workshop on Advancement from Confluence of Emerging Technologies (ACET 2013).

[13] "IBM Centre for Advanced Studies", IBM Systems Journal, Vol. 36.4, 1997.

[14] S. Slaughter, L. Larry, Academic Capitalism: Politics, Policies, and the Entrepreneurial University, 1997. ISBN-0-8018-5549-7

[15] A. Stephan, "Are Public Research Spin-Offs More Innovative?" Working Paper 222, The Ratio Institute, Stockholm and Jönköping University, 2013. http://ratio.se/sv/publikationer/working-papers/2013/no-222-are-publicresearch-spin-offs-more-innovative.aspx.

[16] Srini Chari, "Research computing drives economic development through novel collaborations between gevernments, businesses and higher education institutions," Cabortpartners report, June 2013.

[17] P. Maglio, S. Srinivasan, J. Kreulen \& J. Spohrer, "Service systems, service scientists, SSME, and innovation," Communications of the ACM, 49(7), pp. 81-85, 2006

[18] J. E. Kelly and S. Hamm, "Smart Machines: IBM's Watson and the Era of Cognitive Computing," Columbia Business School Publishing, 2013. http://www.amazon.com/Smart-Machines-Cognitive-ComputingPublishing/dp/023116856X

[19] J. Spohrer, P. Piciocchi, and C. Bassano, "Three frameworks for service research: exploring multilevel governance in nested, networked systems," Service Science 4, no. 2 (2012): 147-160. 